Vulnerable Bodies, Vulnerable Systems

Andreas Philippopoulos-Mihalopoulos, Professor of Law and Theory, School of Law, University of Westminster

School of Law

University of Westminster

$4-12$ Little Titchfield Street

London

WIW 7UW

Email: andreaspm@westminster.ac.uk

Tel: 02079 I 5000

Thomas E. Webb, Faculty Academic Fellow in Law, The Law School, Lancaster University

C58 Bowland North

The Law School

Lancaster University

LAI 4YN

Email: t.webb@lancaster.ac.uk

Tel: 01524594570

\begin{abstract}
In this paper we examine the concept of vulnerability as it relates to the materiality of systems, the exclusion of human physical corporeality, and social exclusion in Luhmann's theory of social autopoiesis. We ask whether a concept of vulnerability can be included in autopoiesis in order to better conceptualise social exclusion and the excluded, with a view to understanding how, if at all, the dangers posed by this exclusion are mitigated by autopoietic processes. We are emphatically not returning to the human subject over operational systems, but seek instead to develop an understanding of the embodied nature of humans and their vulnerability within an autopoietic framework. We argue that the awareness of the risks to social functional differentiation posed by unmanaged exclusion - disenchantment, disassociation, and, most drastically, dedifferentiation provided by our analysis indicates why hyper-exclusion must be mitigated.
\end{abstract}




\section{Vulnerable Bodies, Vulnerable Systems}

\section{Andreas Philippopoulos-Mihalopoulos and Thomas E. Webb*}

\section{Introduction}

In this text we explore humanism, embodiment and vulnerability in terms of autopoietic theory. We examine the exclusion of human physical corporeality and social exclusion in Niklas Luhmann's theory of social autopoietic systems. Our ultimate goal is to explore whether the concept of vulnerability can be included in autopoiesis, thus reconceptualising corporeal and social exclusion and offering ways of better understanding the mechanisms of social marginalisation in, and the risks it poses to autopoiesis.

In what follows we argue that the notion of social (hyper-)exclusion, that is exclusion from access to the operations of functionally differentiated autopoietic systems in toto (such as law, politics, economics and so on), and thus society, if left unmanaged and unmitigated poses a risk to one of the basic tenets of autopoiesis, namely the stable functioning of systems.' Whereas Neves (200I) and Moeller (2006: 59-63) are principally concerned with those left behind by globalisation, 'peripheral societies' (Neves 200I: 263), following Luhmann's discussion in Beyond Barbarism (2008a) of Brazil's favelas, we extend the discussion of under- and over-integration in Neves' work (200I) to the context of societies thought to be "modern" and thus autopoietic. We argue that there is a need to acknowledge, if not the factual existence, then the certain risk, that under-integration (and implicitly over-integration) poses to function systems, and thus to autopoietic society. Individuals excluded by autopoiesis, because of the disassociation and disengagement from society that this entails are liable to seek alternative, non-functional means for resolving their difficulties. In the global

\footnotetext{
"We wish to thank Siobhan Weare for her helpful comments on, and discussion regarding this paper. We also wish to record our thanks to David Campbell, for acting as an intermediary to allow us to secure anonymous reviews, and to the anonymous reviewers for their constructive comments and suggestions. Any errors remain our own.

' We differentiate this form of (hyper-) social exclusion from ordinary exclusion (see 'Exclusion as Erasure' infra) 2 of 35
} 
periphery, where autopoiesis has not developed, this has been termed the risk of 'sabotage' (Moeller 2006: 59; Neves 200I: 264), in the context of autopoietic society however, such activity, where exclusion is not mitigated, may ultimately result in the dedifferentiation of function systems as individuals circumvent functional differentiation in search of a means to overcome their exclusion (consider Verschraegen 2002: 27I).

To demonstrate this we first address the current construction of humans generally, and socially excluded humans specifically, in autopoietic society with reference to universal values and universal human rights, which we find incapable of mitigating hyper-exclusion (contrast with Verschraegen 2002: 262). From here, we turn to how autopoietic systems manage exclusion by erasing their awareness of it, that is, by invisibilising the excluded. Following this, we argue that, in order to manage the underlying risks associated with exclusion (disassociation and disengagement of human, psychic, systems from society, and ultimately dedifferentiation of function systems), autopoiesis needs a concept of the physical body. A concept of the body is necessary because it exposes the material existence of both psychic and social systems, and thereby their vulnerability to the consequences of social exclusion. In short, we ask whether autopoiesis, with its overwhelming focus on social systems, can accommodate the notions of embodiment and vulnerability in relation to exclusion in a way that allows the theory to remain consistent.

The answer we reserve for this is a resounding yes, but not without some caveats. Thus, when we reference the body, we mean both the semantic construct of 'body' that all function systems possess as part of their idea of what a person is (for example, law's legal person, see Naffine 2003; 20II; 2012: 8I-82, Naffine and Owens 1997: 7; and in autopoiesis Teubner 1993: 26; or also protections of the legal body, for example habeas corpus, or the treatment of bodies in medicine); and the body as physical embodiment, corporeality. We use the concept of the body to incorporate a notion of the factually undeniable physical embodiment of humans (see Bottomley 2002: 128; Fineman 2008- 
2009: f9, and in autopoiesis Halsall 2012; Philippopoulos-Mihalopoulos 2007), and their consequent vulnerability, as a means of bringing the concept of materiality to autopoiesis.

In view of this, the autopoietic conceptualisation of embodiment and vulnerability informs our understanding of social exclusion in as much as they indicate that their practical use for overcoming exclusion is restricted by the ensuing awareness of the limits of social change. This, as we will explain, is due to the redundancy generated by the self-referential (negative feedback) loops that permeate social systems through, and indeed as part of, their own autopoiesis. While this does not sound very promising, it is a much-needed antidote to the flurry of rhetoric suggesting that social change happens causally, and is directly connected to human action; this necessity is most evident when viewed in contrast to discourses which imbue law with a profound transformative potential. Although human action does play a role, social change does not come about in the way current and even radical conceptualisations of the law advocate. Rather it requires an understanding of the limits of law's capacity that are revealed through a systemic understanding of vulnerability.

\section{Non-humanism, anti-humanism, dehumanisation}

Let us begin with an exploration of the main autopoietic exclusion, which is that of humans from society. Exclusion in this sense means that the theory does not focus on humans and their actions, but on systems, such as law, politics, mass media and so on, all of which, taken together, comprise society. Autopoiesis reserves several counter-intuitive exclusions from its focus, but none more so, and more polemically debated, than the human exclusion.

Autopoiesis is emphatically a non-humanist theory. It only observes systemic communications, not human actions. In the context of the theory, communications are not understood as human connections but as internal constructions of each system. Thus, the legal system constructs communications, such as legal argumentation, court decisions, statutes and so on, on the basis of its 
systemic code (lawful/unlawful) which determines the boundaries of each system. The total sum of legal communications (namely whatever falls into either of the two values lawful/unlawful) is the legal system; anything else is the system's environment, namely whatever the system is not. This can include other systemic communications (say, political, religious, economic and so on, according to the functional differentiation of the systems), as well as non-communications. Systemic communications are not communicated to other systems but remain within the legal system and form its operations. In other words, communications are neither human operations nor communicable to other systems. This counter-intuitive understanding of communication has further, equally counter-intuitive consequences.

First, although humans form part of the process of production of communication, they are not the causal origin of such communications. Humans are not agents of actions within society, but conduits conveying meaning between and within systems as part of the communicative activity of society (King 2009: 79-82; Luhmann 1992b, p.4II). When a judge decides on a case, she does so in her professional capacity. She will have other characteristics beyond her office, but, in terms of her decision, these parameters can only be accommodated to the extent that they can fit within the way the legal code is applied, how legal thought is structured, and the manner in which legal language is expressed (see also Blaschke, 20I5, on autopoietic agency). Humans have two roles in autopoietic thinking: they are 'semantic constructs' and 'independent autopoietic systems' (Teubner 1993: 26). As constructs they are situated within the system as aspects of the system, such as in the case of the idea of the judge delivering judgment. As independent systems, they exist as people: the actual person of the judge. Both exist simultaneously and separately to one another, the 'personal biases and subjectivity' of the judge being translated into the language of the system (King 1993: 227-228). The same is true of the commercial lawyer acting within a court system and seeking to convince the judge; their personal biases and subjectivity can only be articulated and interpreted through the language of the system because the legal system interprets these communicative utterances through 
its internal semantic construct (Nobles and Schiff 20I3: 250-25I). To approach the system otherwise is to risk being misunderstood, or to be made invisible and inaudible.

The second and most drastic consequence of the communicational focus is that humans, as independent autopoietic systems, are excluded from social systems and society at large. It is clear from the above that the theory is not merely non-humanist but rather anti-humanist. As Moeller (20I2: 2I) puts it,

'[Luhmann] characterizes himself as a radical antihumanist because he thinks that the humanist self-description of society has been fundamentally flawed from the start. The world has never been human, and thus there has never been a shift from a human to a post-human world.'

Luhmann displaces the human not just from the centre, but also the greater focus of the theory, and replaces it with communications. Instead of communicating, humans perceive (a less exigent operation than communication because it does not depend on being selected and communicated, see Luhmann 1995: 4I2) and interact (a reciprocal perception of perception amongst human beings present to one another ${ }^{2}$ ). Both perception and interaction can become communication (Luhmann 1994: 380). Social systems and humans are able to operate as environment to each other, while also maintaining their separation (Luhmann 1992c pp.75-76; see also Philippopoulos-Mihalopoulos 2010: III), thus triggering changes within the other system. As Luhmann (1997) suggests, communicating and perceiving/interacting are complemented by a third modality, that of living. Through the latter, the body puts in an appearance, albeit infrequent, in Luhmann's writings. The connection between mind and body in Luhmann has been the subject of some debate in the literature (Bankowski 1996; Borch, 201I; Cesaratto, 2013; Halsall 2012; Paterson, 1996), and can be summarised as one of

\footnotetext{
${ }^{2} \mathrm{~A}$ boundary of an interaction system is defined along the notion of presence: 'they include everything that can be treated as present and are able, if need be, to decide who, among those who happen to be present, is to be treated as present and who not.' Luhmann, 1995: 412

6 of 35
} 
reciprocal autopoiesis, where one can irritate the other but not have unmediated access to it. Mind and body remain firmly excluded from society (consider Schütz 2009: 237-238).

The theory's anti-humanism should not surprise us. It is in line with (indeed predates) current antiand post-humanist theories, such as new ontologies, posthumanist ethics, new materialisms and so on (see Philippopoulos-Mihalopoulos 2014). Luhmann is unwilling to consider the human as a unity; he has "give[n] up the attempt to 'singularize' the human being” (Moeller 2006: 80; see also Halsall 20I2). In that sense, the argument to return to the subject, and to the human subject in particular in the way humanism and enlightenment theories envisage, has been rehearsed and found lacking (Grear 2007; 20I4). Luhmann has rejected humanistic concepts of society as no longer satisfactory (1997: 3 I; see also Moeller 2008: 127). Autopoiesis has partly fulfilled its radical potential by resisting a world description given over to the facile causalities of human actions (Moeller, 20I2). It describes the complex process of the production of reality, which so often takes place away from human control, without valorising the human. This is one of the hardest paradigm shifts initiated by autopoiesis, because it requires leaving behind "the fiction that played the role of the consolatory companion throughout many centuries of European Dasein” as Schütz (1996: 275) puts it. In autopoiesis, and in what is increasingly becoming our prevalent reality, human actions are deeply mediated by technological loops, financial opacity, political interests, legal complexity, and so on all systemic operations through which human action is understood sociologically.

\section{Values}

The question, however, is whether autopoietic anti-humanism leads to dehumanisation, with potentially catastrophic social consequences, such as disengagement, disassociation and finally exclusion from every aspect of society. ${ }^{3}$ In this context, dehumanisation means that, at least at first

\footnotetext{
${ }^{3}$ As it has become apparent, anti-humanism is a term of art for non-humanist theories and also theories that are against the humanism promoted by Enlightenment. Luhmann falls into this category. Therefore, while "anti-humanist" might 7 of 35
} 
instance and from a legal-political perspective, values ordinarily thought of as integral to a modern democratic society (for example, justice, fairness, and equality) while not irrelevant, are demoted to internal constructions of systems, with their meaning to be determined by the systems' binary codes (see Luhmann 2008b). One cannot attach such values to the operations of systems to modulate the working of the binary coding as in, for example, "just/unjust lawful”/ "just/unjust unlawful”. The autopoietic answer is unswerving: the meaning of such "third" values can only be understood in the context of, and through the operations of the systems in question (Luhmann 1992a, pl47; Luhmann 2008b, particularly pp.27-30; King and Thornhill 2003: 58; see also Neves 200 I: 252-253 and Schütz 201 I: 193); they are meaningless outside this context (Moeller 2006: II6-II7; Teubner 2009). ${ }^{4}$ Indeed, to speak of a democratic, normative political society is to misunderstand the message of autopoiesis (King and Thornhill 2003: 63). These values do not offer a route through which the more comprehensive form of social exclusion, discussed earlier, can be conceived of and managed by autopoiesis (consider Teubner 2009: 8-9). As such, while we might naturally articulate a critique of destitution in a wealthy modern democracy in terms of social injustice or unfairness, this terminology seeks to express the failings of society using pan-social language that elides the specialised understandings that functional differentiation proposes. Autopoiesis indicates that only system specific conceptualisations of both the values and challenges which they are directed towards, can gain any traction (see Moeller 2006 on activism).

The exclusion of the values upon which it is traditionally thought that society is constructed is not easy to accept, yet there is a plausible autopoietic explanation. In the context of a social system premised on identity-generating binary codes, the self-referentiality of that system is what allows society itself to carry on (Luhmann 1992a: 145-I46; Teubner 1993: 15, 27). Placing importance on universal, and often moralising values, and giving them the status of trumps over the decisional

\footnotetext{
ordinarily be defined as against humans, and "dehumanised" as the absence of humans, for consistency with the existing discourse we have adopted what is, perhaps initially, counterintuitive terminology. See also Halsall (20I2)

${ }^{4}$ Schütz (2007: 42), reflecting on the work of Bauman, takes this one stage further in stating that 'A long list of claims, notions, and values, all of immemorial standing, including community, equality, solidarity, indeed "social behavior" ..., are in the process of being made redundant, causally and unspectacularly.'

8 of 35
} 
independence and autonomy of functionally differentiated systems compromises the operation of those systems. Luhmann argues that we must disengage morality from systems, , leading to what Schütz (1994: I58) calls 'a source of anxiety among readers of Luhmann.' In the context of the legal system, for example, the inclusion of moralising values would override systemic operations, resulting 'in the inflexibility of the legal system, [the] obstruction of its selective task, and would have, therefore, dysfunctional effects' (Neves 200I: 253). Thus, it is not appropriate to seek to reincorporate universal values into autopoiesis in a manner which places them over functionally differentiated systems. In any event, the function of autopoiesis is not to create 'a better society' (King 200I: 5; see also Schütz 2009: 237), but to describe and articulate the communicative challenges which modern society faces. Whether or not we are disappointed in this conclusion, it is clear that third values cannot be of any assistance in preventing exclusion. Indeed, no concept is able to prevent exclusion.

Rights

A natural assumption, in the face of the failure if universal values, might be that universal human rights may offer some assistance (see Verschraegen 2002). However,one might consider that they fall into the same or a similar category as third values, attempting to act as an external prism through which systems should construct their understanding, and are, therefore, unhelpful to an understanding of autopoiesis that seeks to mitigate the risks of under-integration and disengagement. However, for Luhmann, universal human rights play a different role to that of third values in society: human rights are, paradoxically, the signifier for the exclusion of human beings from society (Philippopoulos-Mihalopoulos 2010). Before the functional differentiation of modern society, one remained in the social position in which one was born, folding irreversibly into the hierarchical delimitation of one's origin and, hence, one's future (see Luhmann 2008b: 26; see also Moeller 2006: 4I-52; Verschraegen 2002: 26I-262). In pre-modern society there could be no movement between 
systems; this complete integration as a part of a fixed hierarchy amounted to a total or hyperinclusion (see Verschraegen 2002: 265-266).

How, then, was the transition from a situation of total inclusion to specific, deliberate exclusion achieved? Functional differentiation broke up the inflexibility of pre-modern society, and human rights, particularly in the form of liberty and dignity, allowed humans to be reintegrated into a more fluid (though not equal!) society, where they could use rights as a vehicle to alter their social position (see Verschraegen 2002: 264-266): in other words, to move between functionally differentiated systems according to need (Luhmann 2008b: 26). Human rights became the grid on which humans could move and through which their access to various systems was secured. In the bright, new, functionally differentiated society, one has access simultaneously to the legal system, as legal subject; to the political system, as a citizen; to the economic system, as a bank account holder; and so on. In this sense, rights enable everyone to access systems, but it is up to the systems themselves whether or not, and on what terms, this access is granted (Luhmann 2004: 135). Consequently human rights present a somewhat different obstacle to the avoidance of exclusion than that of universalised third values: on the one hand there is a rhetorical exuberance that excludes no one, since rights are supposedly universal and inalienable (Verschraegen 2002: 268); and, at the same time, the factual (lived) experience of rights, the observation of which makes it painfully evident that not everyone is included. One needs to look only briefly at Fortress Europe to understand how, outside of certain parameters, modern society defaults to the old hyper-inclusion model of rights, that is, the absence of rights and the immobilisation of the individual (see, for example, Amnesty International 20 I4: 20, and the 'misery' of society noted by Schütz 2007: 42-43). Where society is placed under stress, and this will occur by degrees, the response is likely to begin targeting regressively those segments of society that are vulnerable by virtue of their under-integration.

Rights only possess a qualified capacity for resistance against ordinary forms of exclusion in the face of the political rhetoric of expediency; that is, they anticipate the opportunity to access systems, 
because it is their purpose to grant this, however, rights cannot, on their own, offer a means of guaranteeing the avoidance of hyper-exclusion (cf Verschraegen 2002: 262). When political entities are so willing to default to this more extensive exclusion (by force if necessary), and to turn to nonfunctionally differentiated modes of operation as an effective (easy) solution, the mere "anticipation of opportunity" offered by rights is an insufficient countermeasure.

The ordinary exclusion of the human is tangibly different from the more comprehensive hyperexclusion. The concept of ordinary exclusion is not an omission or an abstraction, but an overarching theoretical consideration: as Luhmann argues, it is only through excluding the thinking, living and acting presence of human beings from society that a sociological theory can "take human beings seriously.” (Luhmann, 2004: 84, n.19). According to Luhmann, humans are too complex and too unconstrained to be studied sociologically. Humans cannot operate within society (and its operations, its repeating communications, its Kafkian paradoxes, its systemic codes and boundaries). This is why Luhmann reserves for them the space outside society: in order for them to move freely and remain unpredictable. This can be contrasted with hyper-exclusion, where humans remain outside of the society of communications, and unpredictable, but lack the freedom of movement towards society, and in consequence may choose to look elsewhere for solutions to their unfreedom.

Nevertheless, are humans to be left utterly out in the cold? Without the overarching concepts of justice, fairness and equality to direct the operations of society, and in the absence of the umbrella safety of human rights to embrace all human lives equally, autopoietic exclusion bites. Is there nothing we can do about it? Perhaps, but not by changing the theory to mitigate our discomfort with it. Autopoiesis is not, after all, a prescription for a better society but a description of society as it currently is. What is more, it is an immanent description, namely a description that reserves no outside, no better elsewhere (Philippopoulos-Mihalopoulos 2013). Everything that happens and everything that can happen can be found in here, in society and its exclusions. Even the hyper- 
excluded are conceptualised by society through their absence, and are, it seems, thereby abandoned. This immanence is so absolute that it becomes a Nietzschean affirmation (Cesarato 2013): not one that accepts society as it is, but one that confronts society with a clarity that armours one to carry on fighting in spite of a pervasive sense of anxiety borne out of the description offered. This is the value of autopoiesis, and this is how society can change.

\section{Exclusion as Erasure}

The horizontal, absolute and incontestable exclusion that has haunted autopoiesis must now be confronted. This is not, as we have said, the exclusion-as-necessary-condition to take the excluded seriously, but the exclusion as an absolute erasure, where neither third values nor human rights can operate, even in the latter's qualified capacity as an enabling grid. This is the cumulative exclusion from function systems and from society as a whole, eradicated from autopoietic observation even as an indirect source of communication. Luhmann's description (1997, 2008a; see also Neves 200I, Moeller 2006: 59-63) of the Brazilian favelas in the 1990s points precisely to such an exclusion, indeed a hyper-exclusion, where the excluded are not registered by any system. Yet, this hyperexclusion entered autopoietic description, which had seemed to ignore non-Western cultural contexts. Neves (200I) has pointed precisely to this discrepancy: in Brazil's favelas, the rampant exclusion from society is so absolute and cumulative that autopoiesis bears no relation to experienced reality, and in particular to the humans that provide the social events that fuel communication (Neves 200I: 263). However, while Neves postulates that this experience manifests solely in so-called peripheral socieites, we contend that there is no reason why similar exclusion could not emerge in so-called Western, autopoietic society.

Society produces exclusion through its normal functional operations (Moeller 2006: 6I). In recognition of this, society makes some efforts to mitigate the ill-effects of exclusion through the welfare state (Philippopoulos-Mihalopoulos 2010). However, there are limits to the compensatory 12 of 35 
capacity of social security (Luhmann 1990: 22-23), and thus welfare represents only a nominal attempt at overcoming exclusion. Through its welfare operations, society converts its understanding of exclusion into a communicable event, which allows the communication about exclusion to be internalised, preventing further reflection because of its institutionalisation. Thus, we arrive at the uncomfortable conclusion that the welfare state society cares in order not to care (PhilippopoulosMihalopoulos 2010); compensatory mitigation cannot deal fully with social exclusion, just as human rights offer only qualified support.

The limits of mitigation should be seen alongside Neves' criticism of autopoiesis as being unable to describe social exclusion in "less developed" societies (an unsatisfactory label both in his and our

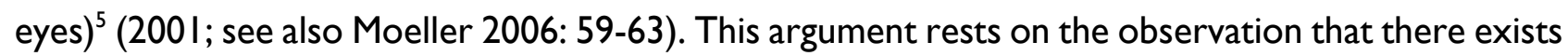
a damaging combination of under- and over-integration into society, allowing hierarchical levels of access and concurrent levels of (dis)benefit. The under-integrated typically lack access to, for example, legal processes, whereas the over-integrated have the capacity to rise above and abuse those processes, and may act with 'impunity' (Neves 200I: 262). Moeller also develops this idea, observing that, in order to participate in the economy, to be able to buy and sell, one must have money, the functional inclusivity of the code of economy is not helpful (2006: 60). As with an inability to assert ones legal rights, a lack of money 'easily leads to exclusion from other systems' (Moeller 2006: 6I).

As we have said, in the West exclusion is partly ameliorated by the welfare state (PhilippopoulosMihalopoulos 2010). However, the social system at large (namely society as the sum of social systemic communications) can only deal to and with that which it has the conceptual capacity to comprehend. Thus, the issues dealt with by welfare state are understood by the system against the backdrop of a construction of itself, situated in a particular temporal and spatial context, and against a unique history that shapes its responses to novelty (see also Schütz 2011: 190-191). In

\footnotetext{
${ }^{5}$ For a critical exploration of the supposed universality and "goodness" of Western values see Schütz, 20II 13 of 35
} 
consequence, the responses that such a system is able to make are limited, not just by its function, but by the situatedness and history against which those codes have come to understand themselves. This does not, however, prevent the possibility that more comprehensive exclusion may also be present for those whose needs the increasingly shrinking welfare state does not anticipate, and those whom systems choose not to address. Such exclusions variously deprive the individual of access to, for example, legal advice and advocacy, housing, personal security, food and water, employment, and political representation. Alternatively, though with the same consequences, individuals may suffer from 'derivative' deprivation brought about through their relationship to someone who has been denied access (Fineman 20I4: 18-19), or due to illness (Fineman 20I4: 20-2I); it is to this construction that we address our critique. The presence of any of these deprivations, direct or derivative, is an indicator that the individual is under-integrated by society, and thus is either wholly or partially excluded, or at risk of exclusion; we argue that there is no reason why this cannot occur in "developed" societies.

The risks inherent in an unmodified, Western-centric, autopoietic framework arise from the inequality of communicative opportunities it generates. That is, despite the presence of ostensibly mobilising human rights (Neves 200I: 262-263), there are those who are immobilised by virtue of their under-integration into a society which denies them access to, for example, the protection and processes of law (Neves 200I: 262; contrast with Verschraegen 2002: 262-263). Although not actually isolated, both because they are recognised (and ignored) by their absence from society, and also because complete isolation is almost impossible for most of humanity in an electronically connected world (Neves 200I: 26I), they are nonetheless constrained and thereby excluded in practice from social systems (Neves 200I: 26I-262). Law is one system which stands to be profoundly affected by this exclusion:

'... exclusion is expanded and intensified resulting in the releasing and generalising of destructive consequences which act against the validity of differentiating legal codes and against the constitution based on the rule of law and which represents the structural coupling of law and 14 of 35 
politics. This is not about a mild meta-difference of inclusion and exclusion in Luhmann's terms, which would mediate the codes of the functional systems and, thus, pervade a functional differentiation of society and the differentiation of law as well as the constitutional order, but rather about the generalised phenomena of exclusion that questions and threatens functional differentiation, the autonomy of law and constitutional normativity.' (Neves 200I: 26I)

In a society where limitations are placed on the equality of opportunity to engage with functionally differentiated systems, the autopoiesis of society is partial. The parsing of autopoiesis exposes the vulnerability of the system and risks dedifferentiation: there is a disjuncture between the apparent accuracy of the operational description offered by autopoiesis, and the levels of autopoietic society that exist below these operations; the physical, the human. This is problematic because the system will be subjected to the sub-dermal pressure to dedifferentiate as those excluded from social processes look to other avenues for answers to their questions and the resolution of their difficulties (see also Verschraegen 2002: 27I, 273); the vulnerable will seek the exposure of vulnerability.

Such discussions as the above, in conjunction with Luhmann's encountering the favelas, and Neves' intense criticism of the autopoietic Western-centrism, are very important on the level of theory. Indeed, this is how protest enters autopoiesis: from within, yet breaking it apart. ${ }^{6}$ It is the visibilisation of the invisible:

“... there are still immense differences between rich and poor, and such differences still affect lifestyle and access to social opportunities. What is different is that this is no longer the visible order, the order without which no order would be possible at all.” (Luhmann, 1997: 772)

Functional differentiation promised an invisibilisation of social inequalities, but now the invisible has become visible (although still not instrumental for society, at least not in the way functional

\footnotetext{
${ }^{6}$ Luhmann, 1989b, especially Chapter 18, and 1996. Luhmann systematically devalues the relevance of protest, both on account of its illusionary transcending quality, and its overproduction of societal resonance. Still, Moeller, 2006, suggests that, had Luhmann the possibility of revisiting the area, he may have come up with different conclusions.

15 of 35
} 
differentiation is) and the hyper-excluded have become registered (see also Fineman 20I4: 14). Society stands in 'embarrassment', on the one hand experiencing the 'unmitigated indifference' promoted by the inclusion/exclusion dynamic, yet on the other in 'stunned silence' (Schütz 2007: 48). No longer limited to non-Western contexts, these invisible exclusions have come to shake the system from within, they are a protest against the visible order. This can only be a good thing.

\section{Bodies}

We have discussed above how autopoiesis deals with the human exclusion, both on the level of theory, as a condition for humans to be taken seriously, and on the level of social exclusion of humans from society, which on the level of theory is seen as the invisible hyper-exclusion. We now propose to examine the concept of embodiment in autopoiesis as a means of introducing the vulnerable corporeality of systems, which, in a way, finds itself at the core of the human exclusion issue. In an interesting article, Halsall (20/2) envisages a way in which bodies could be part of autopoiesis: through their physicality, bodies irritate systems which, in their turn, modify their communications in order to accommodate such irritations. This is what PhilippopoulosMihalopoulos (2007) has called absent environment, namely the materiality of the systemic environment that irritates the system from the inside. While this still holds true, we aim at something more radical here: we are showing how, through the concept of vulnerability that emerges from the materiality continuum between systems and bodies, autopoiesis challenges itself and its various exclusions.

For a theory with biological, material beginnings (Maturana and Varela, 1972 and 1992), Luhmann's sociology is remarkably incorporeal. Both systems theory and autopoiesis have in their bases corporeal processes originating in cells, neurons, ecosystems and so on. Although Luhmann was selective in choosing what he needed from the various theories in order to integrate them into his own grand sociological theory, the exlusion of the material/corporeal is quite striking. It can be 16 of 35 
understood, although not quite justified, if put in the context of its emergence: Luhmann proposed a sociological enlightenment on a scale that could not accept regional, cultural or personal variations. It had to appear solidly abstract and suitably universal in order to appeal to the various situations to which it was designed to apply. In consequence it is assumed that a proper consideration of corporeality would open the theory up to an ungeneralisable amount of variation. The body would upset the mind.

A clear indication of such marginalisation of human embodiment in autopoiesis is the name that Luhmann reserves for humans: 'psychic systems'. Autopoiesis implicitly conflates the concept of the "psychic" system with the idea of incorporeality, presumably because of the non-material commonality between psyche and mind. The particular construction of psychic perceptions and interactions as things that might at some point become systemic communication in a mind/society binary, and the elimination of the human as the object of sociological enquiry has led to the exclusion of the physical body as an object of inquiry, and with this the loss of its spatial and material context.

For a vision of society that is in other respects so radically different from that which has preceded it, the falling back on the old mind/body distinction is problematic for autopoiesis. Indeed, it appears to echo positivism and objectivity, and a reliance on a construction of the human as the liberal subject. The corporeal exclusion has denied the theory access to a wealth of experiences and understandings accessible via the body, such as an examination of historically incorporated structural inequalities. In the absence of sociological tangibility of the body, it is easy to fall back on the interpretive structures, biases, and concepts of the past. This appears to have left autopoiesis behind those radical theoretical enterprises which have sought to supersede the old approaches, such as feminist legal studies, critical legal and socio-legal theory, new materialisms and so on. Autopoiesis needs the body (see Halsall, 20I2).

As a concept, and particularly as an aspect of legal theory, the body has been dealt with extensively by feminist legal theorists. While space does not permit a complete exploration of this rich 
discourse, we must acknowledge the lessons for autopoiesis which can be gleaned from it. Feminist critique of law has exposed the notion of the body in legal thought and theory as essentially the male body (Naffine and Owens 1997: 12; Naffine 201 I: 194-195). The legal theorist who transcends his body to avoid the limitations of the natural, achieving rationality and intellectual purity is inevitably found to be a masculine theorist (Smart 1989: 91). The principle reason why modernist theorists left the body behind, it is claimed, is because any association with the body as a concept integral to understanding social experiences 'seems to cast doubt on the rationality and objectivity of the very mind of the theorist or social scientist' (Smart 1989: 91; see also Bottomley 2002: I30-I3I). In this construction, the female represents the opposite of all that is thought of as central to scientific exploration, indeed it can be seen in binary terms (Smart 1989: 103). Ultimately, the traditional form of legal thinking seeks to render law's construction of bodies genderless, while actually remaining masculine. This has allowed the concealment of vast absences in legal thinking because the female remains an unacknowledged absence in law (Smart 1989: 91-92); such an approach has also permitted hierarchical and discriminatory treatment, and indeed social exclusion on the basis of bodily characteristics that deviate from this norm (Fineman 2014: 21 ). The challenge for feminist legal theory has been to expose this absence, without provoking ingrained beliefs about the binary differences between male and female, or male and others (Smart 1989, pll3; consider also Bottomley 2002: I 14 and Naffine 2004), so as to recognise the experiences of men and women, and men and other categories we might draw upon, as different, and to highlight this difference as being important to legal thinking.

By incorporating the body into law, the embodiment of individuals is recognised as having a direct bearing upon their lived experiences, and how they approach understanding (Bottomley 2002: I27128). It also obstructs the tendency to classify individuals with complex and diverse histories and needs into homogenous 'at risk' groups of, for example, 'undocumented immigrants' or the 'poor' (Fineman 2014: 16). This establishes multiple categories of person as active sites of meaning making, and prevents the law from being thought of as an all-encompassing, all-powerful (male) force, that 18 of 35 
imprints its beliefs, structures, and decisions on an essentially passive (female) body (Bottomley 2002: 132). Importantly, it requires that individuals be recognised as multifaceted, being neither simply (and put simply) female or male, immigrant or citizen, rich or poor, old or young (Fineman 20 14: 16). Reflecting on Deleuze, Bottomley argues that by reintroducing the body as a part of what it is to be a human experiencing society, the body comes to be recognised 'as a site of multiplicity and potential' (Bottomley 2002: I47).

Therefore, in the absence of an explicit, corporeal and material inclusion of the body in autopoiesis, it can be said, in agreement with feminist legal theory, broadly construed, that the human (in his exclusion from the autopoietic legal system and society at large) is constructed as essentially male, taking his cue from a series of acts, precedents, conventions and so on that have been shown to have an essentially male history (albeit one asserted as objective, neutral, rational). That is, the semantic construct of the body that exists in law in the form of the legal person is male, and the lack of an awareness of the physical closes off the opportunity to recognise the inaccuracy of this patriarchally-inspired construct and so confront it (Naffine 20II: 203; see also Weinbach 2013 on gendering autopoiesis to show gender as a form of control mechanism for systems); furthermore, such a construct may not be habitable in reality (Mauthe and Firth 2013: 473). The work of feminist legal scholars indicates that an absence of consideration of the body in law leads to inaccuracies that in turn create inequalities of treatment and access. ${ }^{7}$ This realisation may lead to the exposure of further such inequalities of treatment beyond the female; for example, in relation to physical vulnerability of the body, given that the body of the male is normally portrayed as 'clearly delineated' and 'impermeable' (Naffine and Owens 1997: 12).

Is this, however, equal to an autopoietic opening to materiality? An autopoiesis with an underdeveloped concept of the physical body lacks the richness of experience that the body, as a site of 'potential' that is '(always) in the process of becoming' (Bottomley 2002, I40), may offer. This

\footnotetext{
${ }^{7}$ Others have suggested that the narrower concept of personhood might also be effective Mauthe and Firth 2013 19 of 35
} 
is not, as we have already said, a call to return to the subject, or to place human action at the centre of things. It is instead a call for the development of the concept of the autopoietic body, in order to accommodate a wider range of perceptual and interactive experiences as legitimate experiences that can figure coherently in communication. If at present the legal system operates in such a way as to exclude meaning coming from corporeality, then the inclusion of the latter will allow the legal system to recognise some of the limitations of its present boundaries, and to reassess what it has previously (hyper-)excluded as noise (consider Smart 1989: I I on the classification of certain aspects of the human experience as consisting of non-legal knowledge). Corporeality in autopoiesis would narrowly although inexorably open the theory to the observation of the hitherto invisible and unobservable: the acknowledgement of an outside - what William Rasch (2000a: I 19; see also Rasch 2000b: 210$)$ calls 'the Spasm of the Limits'.

Luhmann was not indifferent to spasms. Indeed, he took them seriously, as his description of the favelas reveals: 'existences reduced to the bodily ... attempting to get to the next day' (2008a: 20; see also Moeller 2006: 62), and 'physical violence, sexuality, the elemental and impulsive satisfaction of necessities' and 'the observation of bodies' (1997: 633). In these later works, an understanding of embodiment from within autopoiesis is sketched. It does not, however, point to well-integrated, well-behaving, normalised bodies whose movement and pause could become, at some point, part of systemic communication. Rather, a different sort of body emerges, hitherto excluded, invisible, but also noisy, fragile, exposed: in other words, vulnerable. It is here that the concept of vulnerability can be seen as key to understanding the autopoietic body, and ultimately as a means of mitigating the risks of hyper-exclusion.

\section{Vulnerability}

Vulnerability, as articulated by Fineman (2008-2009, 20I2, 20I4), has already appeared as a key concept across several areas of legal thought (see for example, FitzGerald 2010; Sherwood-Johnson 20 of 35 
2013; Grear 20II and 20I4; Fineman and Grear 20I4; and Stychin 20I2). In its habitual understanding, vulnerability clashes with autopoiesis: 'vulnerability is - and should be understood to be - universal and constant, inherent in the human condition' (Fineman, 2008-2009: I). ${ }^{8}$ Yet, as will become clear, there is also a close alignment between autopoiesis and Fineman's vulnerability because 'dependency and vulnerability are not deviant, but natural and inevitable' (20I4: I7). Vulnerability is an intrinsic consequence of the material commonality between systems and bodies, as we shall see below. To start with, the factual accuracy of the statement that everything is exposed to 'the ever-present possibility that our needs and circumstances will change' is inescapable (Fineman 2008-2009: 12 , see also pp.8-9; 20I2: 7I, 86). Vulnerability appears to be universal in the same way as the concepts underlying human rights; liberty and dignity. ${ }^{9}$ Indeed perhaps more so, as neither systems nor humans are invulnerable to the changing of conditions nor the entropy of natural processes, or artificial decay. This does not make it a universal concept in the same way as third values or rights. Rather, we suggest that vulnerability aligns with the self-preserving operations of autopoiesis itself in a way that needs to be consistently invisibilised.

Vulnerability exposes the violence of the inequality which flows from both isolated and cumulative hyper-exclusion from society (consider also Fineman 20I4: 24), namely from individual systems and society respectively. The liberal version of the equality/inequality discourse seeks balance through the formally equal treatment of individuals (Fineman 20I4: I4-I6; see also Verschraegen 2002: 274275). On this view, unless unequal treatment of an individual is attached to an aspect of a specific operation of the system, the systemic element of inequality is not addressed (Fineman 2008-2009: 4). Inequality which flows from outside of the control of the system is not part of the system's inclusion/exclusion decision; that someone cannot afford to access the legal system in order to have

\footnotetext{
${ }^{8}$ Note the divergence between Fineman $(2008-2009,2012,2014)$ and autopoiesis in that Fineman places human agency at the centre of her model for overcoming the inequalities perpetuated by the concept of the 'liberal' rather than the 'vulnerable' subject (see Fineman 2008-2009: 13).

${ }^{9}$ At the same time, as with the concept of the body, vulnerability can also exist as a differently understood semantic construct within systems - which may manifest in, as King has observed (I99I) serious difficulties in relation to vulnerable persons, such as children.

21 of 35
} 
the opportunity to be subjected to law's inclusion/exclusion decision is not a concern of formalistic equality measures undertaken by law; it is not within the system. Furthermore, because 'inequalities are produced and reproduced by society' (Fineman 2008-2009: 5), it may appear that such structural inequalities are inevitable. However, these inequalities are 'certainly not natural' (Fineman 2008-09: 5), they are not the inevitable result of societal interaction, but instead are the historical consequence of a particular, and in the case of autopoiesis unquestioned, direction of societal development (Fineman 20I4: 17); vulnerability may be inevitable, but specific inequalities are not.

Despite the impression that autopoiesis may be unnecessarily not just mirroring but perpetuating structural inequalities, it is clear that neither law nor any other system has the ability to change or eradicate social inequalities (consider Fineman, 2008-2009: 5); nor can one seriously advocate the idea of all-inclusion. ${ }^{10}$ What should instead be drawn out from this understanding of inequality is that the individual experience of vulnerability always exists, in a particularised and personal way, within a wider network of systemic inequalities and imbalances (Fineman 2008-2009: 10). Not everybody is able, or indeed enabled, to engage equally well with society, either in the playing of particular roles (for example, employee, parent, citizen), or through interaction with other psychic systems (such as lawyers and doctors). This is largely because of the variable ability of humans to emulate the liberal subject (2008-2009: II; 20I2: 84; 20I4: 14). Humans are not, therefore, afforded equality of opportunity to engage with systems, even if those systems should then reject their efforts as irrelevant or misconceived (the feminist critique of law's deafness, why it chooses to reject, should not be forgotten, but space does not permit an exploration of this here, see further Smart 1989).

This form of inequality bears a close resemblance to the problems Neves indicated in relation to over- and under-integration (200I: 26I-263). It recognises that although the inequalities brought about by the exposure of one's vulnerability might be confined to each system (for example, a lack of access to legal advice, a lack of employment), their effect is cumulative, and the resulting exclusion

\footnotetext{
${ }^{10}$ Fineman herself recognises the impossibility of all-inclusion, albeit using different terms, speaking of the possibility of lessening vulnerability, rather than eradication of vulnerability, 2008-2009: 10

22 of 35
} 
total. In the same way as the denial of fundamental human rights prevents access to, movement within and between systems, an under-integrated individual, where their vulnerability is exposed, is also ejected from, or never permitted in the first place to approach, the social system. The problem of under-integration is, therefore, not to be seen as unique to 'peripheral societies' of limited functional differentiation, but as a risk to all societies (contra Neves 200I: 263). The vulnerability of the embodied human demonstrates that we are all at risk of losing access to social communication, as the recent European Union financial and social crises have demonstrated beyond doubt.

\section{Materiality Continuum}

The above makes vulnerability an ontological constant of autopoiesis without, however, making it a universal one." The operation of vulnerability emerges from a concept only occasionally employed by Luhmann that underlines (ontologically, we would say) all autopoietic operations: the materiality continuum. Luhmann writes:

\footnotetext{
“...the establishment and maintenance of system boundaries - including those of living beings - presuppose a materiality continuum that neither knows nor respects those boundaries". (1997: 54)
}

The continuum brings together (while separating) all three modalities; the social (communication), the psychic (interaction and perception), and the corporeal. At the same time, however, and this is one of the greatest autopoietic paradoxes, the materiality continuum must be excluded from autopoietic considerations:

\footnotetext{
1 Ontology is not prima facie compatible with autopoiesis, which claims to be radically epistemological; see however Philippopoulos-Mihalopoulos, 2013; Rasch, 2013.

23 of 35
} 
'... whenever there is an emergent order, we find that the elements of a presupposed materiality- or energy-continuum are excluded. Total exclusion is the condition of emergence' (1992d: 144I)

A materiality continuum is presupposed, yet necessarily excluded by each modality in an attempt to establish and maintain its autopoiesis. In that sense, humans, animals, objects, ideas, and indeed systems, are all embodied in this continuum; but its omnipresence must be excluded for the sake of the emergent order of autopoiesis (this can be contrasted with Actor-Network Theory, see Mauthe and Webb 20l3). And just as one can talk about vulnerable human bodies, or indeed fragile things (Connolly, 2013), in the same way one can talk about vulnerable (or fragile) systems (see Verschraegen 2002: 27I). The very need to invisibilise the materiality continuum that brings all operations together, exposes systems to the vulnerability of a constant battle of differentiation against dedifferentiation. The foundational gesture of autopoiesis, the line that separates a system from its environment, is in itself a defensive mechanism, and in turn a clear indication of systemic vulnerability. The reason for the relative closure of autopoiesis rests in an acknowledgement of the risk, perhaps even the fear of melting away among the velocity of the continuum. This is the autopoietic meaning of vulnerability in its most foundational sense: to be thrown into material continuum, trying to keep oneself together while battling against the irresistible dissolution of the outside (see further Philippopoulos-Mihalopoulos 201 I).

Vulnerability is thus a material and embodied concept, the meaning of which becomes evident when seen in relation to materiality continuum. This is also the reason for which it can be accommodated in autopoietic thinking. As with materiality continuum, vulnerability brings together social systems, psychic systems and matter, and opens up new communicative possibilities at the functional and psychic levels of society. As with materiality continuum, vulnerability must be internalised in each system, and each body, in order to emerge' namely to establish and continue autopoiesis. Finally, vulnerability goes to the core of each system and each body, yet it must be put aside, kept excluded. Consider the risk of systemic dedifferentiation: the destabilisation of specialised systems of 24 of 35 
operation due to novelty, catastrophe, or simple inadequacy. Dedifferentiation, which may manifest in the falling-back on the use of arbitrary force to resolve political disagreement, political expediency to counteract legal impasse, or economic corruptibility across other function systems, destabilises the ordinary reproductive workings of function systems by ignoring and circumventing them (see also Verschraegen 2002: 273-274). It is for this reason that Luhmann (2004) urges against dedifferentiation. Consequently, differentiation has become the autopoietic fetish par excellence (what Schütz (1994) calls Luhmann's cryptonormativities). The fear, or realisation of, for example, politics or law being taken over by a system such as economy or religion, thereby becoming dedifferentiated, would signal, for Luhmann, the end of modernity. Regardless of the fact that this might indeed already be happening in some way or other (Philippopoulos-Mihalopoulos 2010), the point of interest here is that the command "do not dedifferentiate" resonates with this other command: "hide your vulnerability". Do not allow the outside to come in and alter you. Systemic identity is a fragile, volatile, constructed thing, characterised by vulnerability through and through. But indulging this vulnerability does not help autopoiesis.

\section{Autopoietic Vulnerability and Hyper-Exclusion}

Can this kind of autopoietic vulnerability help the hyper-excluded human? It is very doubtful that on a practical level it could have a direct effect. As we have said, no concept as such can change social conditions, even human rights only open up the possibility of movement within society. What human rights and vulnerability do, however, is allow individual identification, encourage awareness of needs and lacks, and help mobilise towards their realisation. In this sense, autopoietic vulnerability can help. First, it intervenes in the vulnerability discussion with a pragmatic, measured approach. By first alerting us to the need for a concept of the physical body in autopoiesis, and then extending vulnerability to bodies and systems alike, one understands that all involved are equally burdened by the need to deal with vulnerability: by excluding it from awareness/communication (this is not the 
'burying' of the dependency of the vulnerable within private life referred to by Fineman 2014: 18). This, of course, always leads to more vulnerability because it cuts off avenues of solidarity and collective action in terms of human bodies, or more adventurous, deeper structural couplings between systems. Hiding vulnerability is itself an act that exposes more vulnerability. And this vulnerability autopoietically reproduces itself, locked up in isolated instances of systemic and corporeal closure.

This understanding of vulnerability seeks to manage the resultant underlying pressure to dedifferentiate as a means of finding a better mitigation for hyper-exclusion, by counselling against the wider risks to society that following this path would entail (autocratic populist dictatorships having already harmed both individuals and systems in this way, see Verschraegen 2002: 27I). In this sense, there is some autopoietic truth to Fineman's argument that 'our vulnerability and the need for connection and care it generates are what make us reach out and form society' (Fineman 20I4: 22). The communicative exclusion of vulnerability is thus not the same as its suppression; the threat of dedifferentiation means that, even in its absence, it remains ever-present and cannot be ignored, it demands that systems actively seek the means to increase access to avoid the risk of vulnerability exposure.

Second, it shows the limits of the potential of systems and human bodies alike, especially in relation to each other. The liberal idea of all-inclusion (based, of course, on one's assumed ability to be part of the system, see further Fineman 2014: 14-16) is undermined through the above approach. But even the equivalent critical utopia of all-inclusion, this time not on the (neo)liberal understanding of 'personal potential', but in terms of the more socially aware expansion of the welfare state, international aid, regional solidarity and so on, is itself shown to be exposed to the vulnerability that comes from the inability of systems to dedifferentiate as a solution to exclusion (and therefore expose their vulnerable identity to the materiality continuum). This points to a measured understanding of how much effect human action can have, whether in terms of its everyday 
mobilisation, or in terms of more radical interventions such as protest, revolt or revolution. We have witnessed all of these in the last decade or so, in varying contexts that spread from Cairo's Tahrir Square to Athens' Syntagma Square and London's St Paul's. We have also witnessed how slowly, indeed if at all, systemic operations have registered these, and what kind of innovation they initiated (or indeed how much redundancy won the day). Change does not come in a causally determined or even traceable way. Change of that magnitude requires a sustained, multi-lateral, and causally complex persistence, which society itself (in the sense of function systems) resists.

What we can recognise however, is that legal thinking is finally turning spatial, corporeal, material. With it, so does legal autopoiesis, and autopoietic thinking at large. Autopoiesis is a theory with immense potential, both because of its ability to describe society in a counter-intuitive yet actual way, but also because it shows clearly the limited expectations that one can have of systems and their communications. Introducing corporeality and vulnerability to autopoiesis brings to the theory the kind of spasms which allow it to develop further by opening up communicative possibilities that demand answers, structural reflection, and novel communication.

\section{Conclusion}

In expanding Luhmann's previously underdeveloped thinking on corporeality, we have demonstrated that autopoietic and psychic (human) systems are exposed to the shearing forces of the materiality continuum because of their physical embodiment. In so doing, we have shown that the vulnerability disclosed by a recognition of materiality is a vital concept for autopoiesis, particularly when the autopoietic description of society offers a picture of increasing tension and strife. This confirms and builds upon Neves' observation by explaining not only that the under- and over-integration of individuals towards function systems is problematic for "peripheral" societies, but also that it poses significant risks to what are traditionally conceived of stable autopoietic social systems. In view of this we have explained that, while autopoiesis may be able to successfuly invisibilise the excluded (both hyper- and ordinary), the failure to remain aware of the existence of that absence at all times 
exposes society to the risks of disassociation, disengagement and, most radically, dedifferentiation, for the simple reason that the excluded seek alternative means, outside society, to register their exclusion.

APM, TEW 2015 


\section{Bibliography}

Amnesty International (20I4), The Human Cost of Fortress Europe, available at http://www.amnesty.eu/content/assets/Reports/EUR_050012014_Fortress_Europe_compl ete_web_EN.pdf last accessed 22.07.15

Bankowski, Zenon (1996) 'How does it Feel to be on Your Own? The Person in the Sight of Autopoiesis' in David Nelken (ed.) Law as Communication. Aldershot: Dartmouth

Blaschke, Steffen (20I5), 'It's All in the Network: A Luhmannian Perspective on Agency', Management Communication Quarterly 29(3):463-8

Borch, Christian (20II) Key Sociologists: Niklas Luhmann. London: Routledge.

Bottomley, Anne (2002) ‘The Many Appearances of the Body in Feminist Scholarship’ I27-I48, in Andrew Bainham, Shelley Day Sclater, Martin Richards (eds.) Body Lore and Laws. Oxford: Hart

Cesaratto, Todd (2013) 'Luhmann, All Too Luhmann: Nietzsche, Luhmann and the Human' in Luhmann Observed: Radical Theoretical Encounters, ed A. la Cour, and A. PhilippopoulosMihalopoulos. Basingstoke: Palgrave.

Connolly, William (2013), 'The “New Materialism” and the Fragility of Things', Millennium - Journal of International Studies 41:399-4I2

Fineman, Martha, A (2008-2009) 'The Vulnerable Subject: Anchoring Equality in the Human Condition', Yale Journal of Law and Feminism 20:1-23

Fineman, Martha, A. (20I2) “'Elderly” as Vulnerable: Rethinking the Nature of Individual Responsibility and Societal Responsibility' The Elder Law Journal 20:7 I-I I 2 
Fineman, Martha, A. (2014) 'Equality, Autonomy, and the Vulnerable Subject in Law and Politics' in Martha A. Fineman and Anna Grear (eds.) Vulnerability: Reflections on a New Ethical Foundation for Law and Politics. London, Ashgate

Firth, Georgina, and Barbara Mauthe, (2013) 'Refugee Law, Gender and the Concept of Personhood' International Journal of Refugee Law 25(3): 470-50I

FitzGerald, Sharon A. (2010) 'Biopolitics and the regulations of vulnerability: the case of the female trafficked migrant' International Journal of Law in Context 6:277-294

Grear, Anna, (2007) 'Challenging corporate 'humanity': legal disembodiment, embodiment and human rights', Human Rights Law Review, 7(3):5 I I-543

Grear, Anna (20II) 'The vulnerable living order: human rights and the environment in a critical and philosophical perspective', Journal of Human Rights and the Environment 2(I):23-44

Grear, Anna (20I4), 'Vulnerability, advanced global capitalism and co-symptomatic injustice: locating the vulnerable subject', in Martha A. Fineman and Anna Grear (eds.) Vulnerability: Reflections on a New Ethical Foundation for Law and Politics. London, Ashgate

Halsall, Francis (2012) 'Niklas Luhmann and the Body: Irritating Social Systems', The New Bioethics 18(I): 4-20King, Michael (1993) 'The 'Truth' About Autopoiesis', Journal of Law and Society $20(2): 218-236$

King, Michael (199I), 'Child Welfare within the Law: The Emergence of Hybrid Discourse' Journal of Law and Society 18(3): 303-322

King, Michael (200I) 'The Construction and Demolition of the Luhmann Heresy', Law and Critique 12:1-32

King, Michael (2009), Systems, not people, make society happen, Edinburgh: Holcombe Publishing 
King, Michael and Christopher Thornhill (2003) Niklas Luhmann's theory of politics and law. London: Palgrave

Luhmann, Niklas (1989a), 'Law as a Social System', Northwestern University Law Review, 83(I\&2): I36150

Luhmann, Niklas (1989b), Ecological Communication (trans. J. Bednarz, Jr.). Cambridge, Polity Press

Luhmann, Niklas (1990), Political Theory in the Welfare State. New York: de Gruyter

Luhmann, Niklas (1992a) 'The Coding of the Legal System' in Gunther Teubner and Alberto Febbrajo (eds.) State, Law, and Economy As Autopoietic Systems: Regulation and Autonomy in a New Perspective. Milan: Giuffrè, I45-I85

Luhmann, Niklas (1992b), 'Some Problems With <<Reflexive Law>>' in Gunther Teubner and Alberto Febbrajo (eds.) State, Law, and Economy As Autopoietic Systems: Regulation and Autonomy in a New Perspective (European Yearbook in the Sociology of Law, Double Issue). Milan, Giuffrè

Luhmann Niklas (1992c) 'The Concept of Society’ Thesis Eleven 31:67-80

Luhmann Niklas (1992d), 'Closure and Structural Coupling', Cardozo Law Review 13(5): 1419-I442.

Luhmann, Niklas (1996), Protest: Systemtheorie und Soziale Bewegungen. Frankfurt: Suhrkamp

Luhmann, Niklas (1997) Die Gesellschaft der Gesellschaft. Frankfurt am Main: Suhrkamp.

Luhmann, N. (2004) Law as a Social System (trans. K Ziegert, ed. F. Kastner, R. Nobles, D. Schiff and R. Ziegert). Oxford, Oxford University Press.

Luhmann, Niklas (2008a), 'Beyond Barbarism', Soziale Systeme I4(I): 38-46 (first translated and published trans. H. G. Moeller, in H. G. Moeller (2006) Luhmann Explained, Chicago: Open Court) Luhmann Niklas (2008b) 'Are There Still Indispensable Norms in Our Society?' Soziale Systeme I4(I): 18-37.

31 of 35 
Maturana, Humberto and Francisco Varela (1972) Autopoiesis and Cognition: the Realization of the Living. Dordecht, Holland: Reidel Publishing

Maturana, Humberto and Francisco Varela (1992) The Tree of Knowledge: the Biological Roots of Human Understanding. Boston: Shambala

Mauthe, Barbara and Thomas E. Webb, (2013) 'In the multiverse what is real?: Luhmann, complexity and ANT' in Anders La Cour and Andreas Philippopoulos-Mihalopoulos (eds.), Luhmann Observed: Radical Theoretical Encounters. Basingstoke, Palgrave

Moeller, Hans-Georg (2006) Luhmann Explained: From Souls to Systems. Chicago, Open Court

Moeller, Hans-Georg (2008) “'Human Rights Fundamentalism’ The Late Luhmann on Human Rights", Soziale Systeme I4(2): I26-I4 I

Moeller, Hans-Georg (20I2) The Radical Luhmann, New York: Columbia University Press

Naffine, Ngaire (2003) 'Who are Law’s Persons?' Modern Law Review 66(3): 346-367

Naffine, Ngaire (20II) 'Llberating the Legal Person', Canadian Journal of Law and Society 26(I): 193203

Naffine, Ngaire (20I2), 'Legal personality and the natural world: on the persistence of the human measure of value' Journal of Human Rights Law and the Environment 3:68-83

Naffine, Ngaire, and Rosemary J. Owens (1997) 'Sexing Law' in Ngaire Naffine and Rosemary J. Owens (eds.) Sexing the Subject of Law. New South Wales, Australia, LBC Information Services, Sweet and Maxwell. pp.3-24

Neves, Marcelo (200I) 'From the Autopoiesis to the Allopoiesis of Law' Journal of Law and Society, $28(2): 242-264$

Nobles, Richard and David Schiff (2013) Observing Law Through Systems Theory. Oxford, Hart, 2013 
Paterson, John (1996) 'Who is Zenon Bankowski Talking to? The Person in Sight of Autopoiesis' in David Nelken (ed.) Law as Communication. Aldershot: Dartmouth Publishing

Philippopoulos-Mihalopoulos, Andreas (2006) 'Dealing (with) Paradoxes: On Law, Justice and

Cheating, in Michael King and Christopher Thornhill, Luhmann on Law and Politics, Critical Appraisals and Applications. Portland, Oregon: Hart Publishing

Philippopoulos-Mihalopoulos, Andreas (2007) Absent Environments. London: Routledge

Philippopoulos-Mihalopoulos, Andreas (2010) Niklas Luhmann, Law, Justice, Society. London:

Routledge

Philippopoulos-Mihalopoulos, Andreas (20II) ““...the sound of a breaking string”: Critical

Environmental Law and Ontological Vulnerability', Journal of Environmental Law and Human Rights, 2(I): 5-22.

Philippopoulos-Mihalopoulos, Andreas (2013) 'Folding Autopoiesis: Between Luhmann and

Deleuze' in Anders La Cour and Andreas Philippopoulos-Mihalopoulos, Luhmann Observed: Radical Theoretical Encounters (eds.). Basingstoke, Palgrave.

Philippopoulos-Mihalopoulos, Andreas (2014) 'Critical Autopoiesis and the Materiality of Law', International Journal of Semiotics of Law 27(2): 165- I77

Rasch, William (2000a) Niklas Luhmann's Modernity: The Paradoxes of Differentiation. Stanford, Stanford University Press

Rasch, William (2000b), 'The Limit of Modernity: Luhmann and Lyotard on Exclusion', in William Rasch, William and Cary Wolfe (eds.), Observing Complexity: Systems Theory and Postmodernity. Minneapolis, University of Minnesota Press

Rasch, William (20I3), 'Luhmann's Ontology' in Anders La Cour and Andreas PhilippopoulosMihalopoulos, Luhmann Observed: Radical Theoretical Encounters (eds.). Basingstoke, Palgrave 
Schütz, Anton (1994) 'Desiring Society: Autopoiesis beyond the Paradigm of Mastership', Law and Critique 5(2): 149-64

Schütz, Anton (1996) 'The Twilight of Global Polis: On Losing Paradigms, Environing systems and Observing World Society', in Gunther Teubner (ed.) Global Law without a State, Aldershot: Ashgate, 1996

Schütz, Anton (2007) ‘How aufarbeiten ‘Liquid Society’? Zygmunt Bauman’s Wager’ in Přibáň, Jiří (ed.) Liquid Society and Its Law. Aldershot, Ashgate. pp.4I-60

Schütz, Anton (2009) 'Imperatives Without Imperator' Law and Critique 20:233-243

Schütz, Anton (20II), ‘A Quandary Concerning Immanence’ Law and Critique 22:189-203

Sherwood-Johnson, Fiona (20I3), "Constructions of "vulnerability” in comparative perspective:

Scottish protection policies and the trouble with 'adults at risk', Disability \& Society 28(7):908-921

Smart, Carol (1989) Feminism and the Power of Law, London, Routledge

Stychin, Carl (20I2), 'The vulnerable subject of negligence law', International Journal of Law in Context, 8:337-353

Teubner, Gunther (1988), 'Evolution of Autopoietic Law' in Gunther Teubner (ed.) Autopoietic Law: A New Approach to Law and Society, New York and Berlin, Walter de Gruyter Publishing.

Teubner, Gunther (1993), Law as an Autopoietic System. Oxford, UK \& Cambridge, Mass., USA: Blackwell

Teubner, Gunther (2009) 'Self-subversive Justice: Contingency or Transcendence Formula of Law?' Modern Law Review, 72(I): I-23

Verschraegen, Gert (2002) 'Human Rights and Modern Society: A Sociological Analysis from the Perspective of Systems Theory' Journal of Law and Society 29(2): 258-28I 
Weinbach, Christine (20I3), 'Gendering Luhmann: The Paradoxical Simultaneity of Gender Equality and Inequality' in Anders La Cour and Andreas Philippopoulos-Mihalopoulos, Luhmann Observed: Radical Theoretical Encounters (eds.). Basingstoke, Palgrave. 